\section{The Third Order Nonlinear Optical Properties of Gold Nanoparticles in Glasses, Part II*}

\author{
Daven Compton, Lesley Cornish, Elma van \\ der Lingen \\ Mintek, Private Bag X3015, Randburg, 2125, \\ South Africa \\ Email: DavenC@mintek.co.za
}

\begin{abstract}
The optical properties of gold nanoparticles have been known for a number of years and recent advances in laser power have now allowed the non-linear optical properties to be studied. In this short review paper, the various theories that have been used to describe the optical properties of gold nanoparticles are presented. Methods of preparing gold nanoparticles in glasses are explained briefly, as well as characterization techniques. The optical properties of gold nanoparticles are reviewed, as well as the effects of particle size, shape, concentration and c.
\end{abstract}

*Part I published in Gold Bulletin 36 (1) page 10

\section{Effects Of Nanoparticle Size}

The relationship between optical properties and nanoparticle radius has been studied in glasses with dispersed colloid Au nanoparticles $(111,112)$. The peak plasmon wavelength shifts continuously to longer wavelengths with increasing average particle radius. A similar dependence was seen in silica glasses dispersed with Au colloid particles (112,113). Foss et al. (68) found significant transparency in the near-IR region and strong extinction in the visible for particles with nearsphere like shape. The wavelength of maximum extinction increased with increasing particle radius, giving rise to colour variations (red-purple for $30 \mathrm{~nm}$ size and blue-green for 60 $\mathrm{nm}$ size). This is shown in Figure 1. This was consistent with the findings of Mie (17). Hosoya et al. (73) and Muto et al. (102) found in $\mathrm{Au}: \mathrm{Al}_{2} \mathrm{O}_{3}$ thin films that the spectra broadened and the peak shifted to longer wavelengths as the particle size decreased. Muto et al. (102) explained it as due to charge transfer from the metal particles to the amorphous oxide by the aluminium-metal bonds used in adhesion. The decreased electron density of the metal particles gives rise to the blue-shift. This behaviour was opposite to that of $\mathrm{Au}: \mathrm{SiO}_{2}$, and indicates that the matrix has an effect on the blue- or red-shift of the plasmon peak with size.

As the wavelength of the surface plasmon resonance changes with particle size, the $\chi^{(3)}$ is also expected to change with size. Fukumi et al. (60), found $\chi^{(3)}$ to be approximately proportional to the fourth power of the particle radius. They also found that $\chi_{\mathrm{m}}{ }^{(3)}$ (of the metal particles on their own) had negligible dependence on the particle radius. The value of $\chi_{m}{ }^{(3)}=2.5 \times 10^{-8}$ esu agreed with that of Hache et al. (32) and Bloemer et al. (114).

Hornyak et al. (69) prepared Au nanoparticles in nanoporous alumina membranes, and absorption properties for nanoparticles of size $52 \mathrm{~nm}$ down to $16 \mathrm{~nm}$, and with various aspect ratios. They used a modified form of MG theory, called the dynamic MG (DMG) theory (68), to model the optical properties. They found that as the nanoparticle size decreased, the wavelength of the maximum absorption intensity $\lambda_{\max }$ approached the value predicted by DMG theory. For the smallest diameter particles, $(16 \mathrm{~nm})$, the values were identical with DMG theory, and they suggested that there was a quasi-static DMG limit ( $\lambda_{\max }$ does not change from $\sim 508 \mathrm{~nm}$ ) for nanoparticles of diameter $16 \mathrm{~nm}$.

Alvarez et al. (115) prepared passivated gold particles with sizes 1.4-3.2 nm. They found that with decreasing size, the SPR band broadened until it became unidentifiable for sizes less than $2 \mathrm{~nm}$. They also found a distinct onset for strong absorption near the energy $(\sim 1.7 \mathrm{eV})$ of the interbandgap $(5 d \rightarrow 6 s p)$. Above this onset, a weak steplike structure was found. The experimental results were compared with Mie 


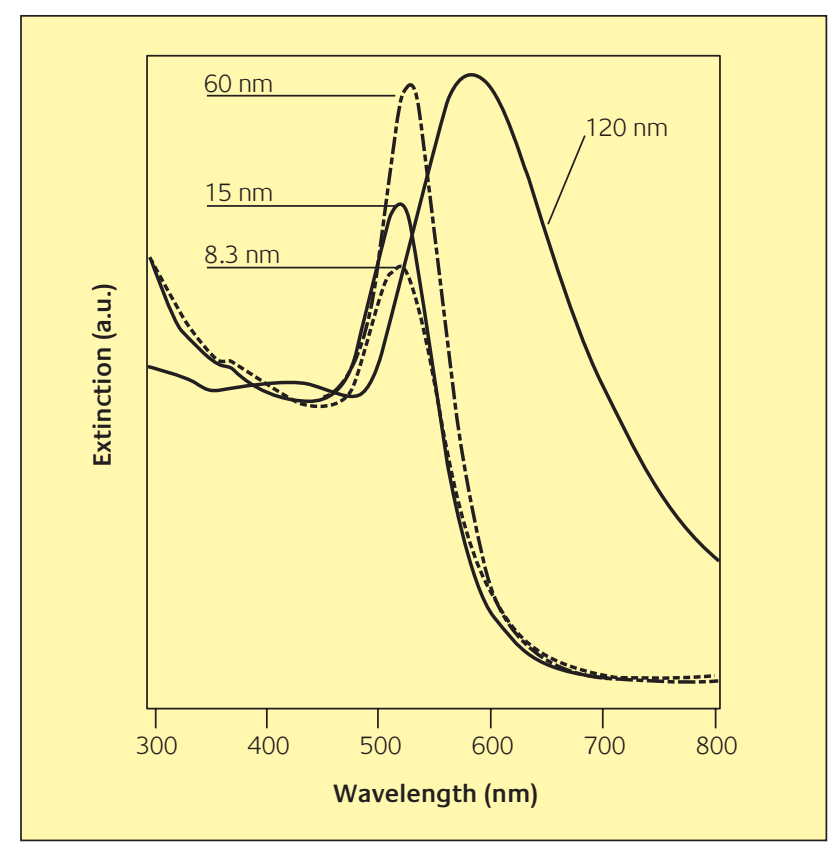

Figure 1

The Absorption Spectra of Different Sized Au Particles (99)

theory, and good agreement was found when the passivated layer was accounted for. They also suggested that there was a critical size of $\sim 2 \mathrm{~nm}$, below that the electronic structure changes dramatically. Palpant et al. (49) reported that the SPR blue-shifts with decreasing cluster size (2.0-3.7 $\mathrm{nm})$. There was also increased damping and broadening of the absorption band, agreeing with Alvarez et al. (115). Palpant et al. (49) applied theoretical time-dependent localdensity-approximation (TDLDA) calculations to their results, and found good agreement. In this theory, the conduction electrons are treated quantum-mechanically, whereas the optical properties of the matrix and ionic core background are treated classically through bulk-like dielectric functions. They explained the effects as follows: they considered the cluster to have two-regions, an inner medium and an outside shell. The blue-shift with decreasing size was due to the screening effects, due to the polarisable inner medium, that vanish in the shell of the particle.

\section{Effects Of Nanoparticle Shape}

For gold nanorods in an aqueous solution, the plasmon absorption splits into two bands $(116,117)$, corresponding to the response along and perpendicular the long axis of the rods. The transverse mode (end on) corresponds to the simple case of spherical particles. The longitudinal mode (length-wise) is red-shifted, and depends strongly on the nanorod aspect ratio.

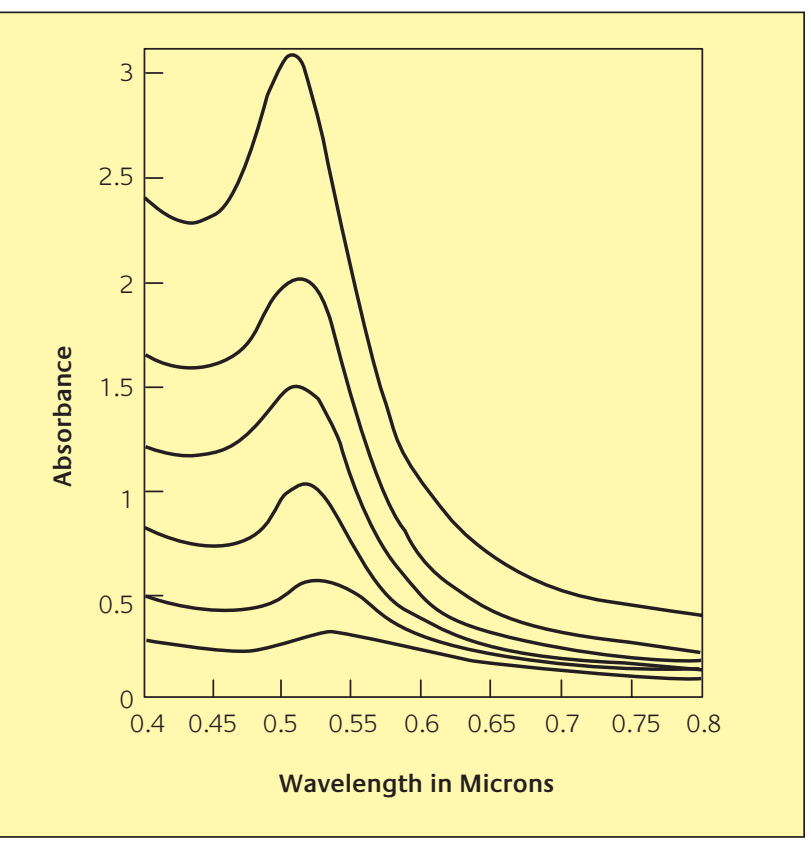

Figure 2

Absorption Spectra (due to the transverse plasmon resonance) for 32 nm Diameter particles with Different aspect Ratios. The Uppermost Curve is for the Highest Aspect Ratio, and the Lowermost Curve is for the Lowest Aspect Ratio Nanoparticle (69)

The colour of an $\mathrm{Au}: \mathrm{Al}_{2} \mathrm{O}_{3}$ composite can be varied by changing the shape of the Au particles in the matrix (oriented gold nanorods). As the aspect ratio increases (with constant diameter), the extinction intensity increases and the extinction maxima wavelength is blue-shifted to shorter wavelengths (68). By varying the aspect ratio, systematic shifts in the extinction maxima can be attained. This is shown in Figure 2. When the cylinder radius is increased, the extinction maxima red-shifts to longer wavelengths. The effects of the aspect ratio follow qualitatively the predictions of MG theory.

Foss et al. (118) compared the transmittance of $\mathrm{Au}$ microcylinders (0.26 $\mu \mathrm{m}$ diameter) in $\mathrm{Al}_{2} \mathrm{O}_{3}$ membranes to that of Maxwell-Garnett and Bruggeman (33) theories. They found qualitative agreement between experimental and theory. It was considered that the particle separation in the matrix was not small relative to the wavelength, creating a phase lag between the incident and induced fields experienced by a given particle (called retarded polarisation (119)). By modifying the MG theory to take this particle separation into account, the theory followed the experimental data reasonably. They also systematically varied both aspect ratio and diameter, and compared the optical spectra with predictions of MG theory and Mie theory (68). They had qualitative agreement with the two theories, and proposed a modification of the MG theory using dynamical models for the depolarisation factor (120), to take into account size and shape effects in a unified calculation. 


\section{Effects Of Gold Concentration (Volume Fraction)}

Liao et al. (48) reported that in $\mathrm{Au}: \mathrm{SiO}_{2}$, at 5\% Au concentration, the wavelength of the surface plasmon resonance (SPR) was close to $520 \mathrm{~nm}$. With increasing Au concentration, the SPR peak shifted to $530 \mathrm{~nm}$ at 21\% Au, and $540 \mathrm{~nm}$ at 45\% Au. Accompanying the shift was a sharpening of the SPR (due to the size increase of the Au clusters). However, at greater concentrations, the peak intensity decreased while the offresonant absorption increased. The absorption spectra became completely different when the Au concentration reached the percolation threshold. At Au concentrations higher than the percolation threshold, there was a transmission window in the resonant region, consistent with theoretical predictions (121). Liao et al. (48) reported the susceptibility $\left(\chi^{(3)}\right)$ as $\sim 2.5 \times 10^{-6}$ esu for co-sputtered $\mathrm{Au}: \mathrm{SiO}_{2}$ films. With increasing $\mathrm{Au}$ concentration, the susceptibility increased quickly and reached a maximum of $\sim 2.5 \times 10^{-6}$ esu at $40 \%$ Au. The effect of gold concentration is shown in Figure 3. This maximum value was three orders of magnitude larger than the value at 4\% Au (3.5 $\times 10^{-9}$ ) esu, and at least 10 times higher than that reported by Tanahashi et al. (105). The rapid increase of $\chi^{(3)}$ was due mainly to the enhancement of mutual interactions between the $\mathrm{Au}$ clusters, whereas at higher Au concentrations, the particle size becomes large so that only the outer layer of the Au particles contributes to the optical nonlinearity.

The laser pulse width will affect the values of $\chi^{(3)}$, as $\chi^{(3)}$ contains two components: a fast and slow component $(19,122)$. Comparison of the results of Liao et al. (48) and Tanahashi et al. (105) show that there is a difference in measured values due to the difference in the laser pulses used. Bearing this in mind, values of $\chi^{(3)}$ near $40 \%$ Au could be as large as $5 \times 10^{-5}$ esu for nanosecond pulses.

The effective $\chi_{\text {eff }}^{(3)}$ for low concentrations is linearly proportional to the metal concentration (19). The linear relationship is only valid up to $15 \% \mathrm{Au}$, and beyond that the relationship is no longer linear (48). Liao et al. (48) have found a power law dependence of the $\chi^{(3)}$ on $\mathrm{Au}$ concentration $p\left(\chi^{(3)} \sim p^{t}\right)$ where $t$ is approximately 3 .

Liao et al. (48) suggested the enhancement of $\chi^{(3)}$ at high Au composition was the result of two effects: (1) the socalled local field enhancement due to the resonance of the probe beam within the cavities formed by the Au clusters, and (2) due to Mie resonance of the Au particles which would enhance the local field inside and outside the Au particles. When the first effect is considered at high Au concentrations (Au particles become connected), the large local field will be averaged out and the effect reduced, decreasing the $\chi^{(3)}$.

Liao et al. (48) reported the figure of merit (without the time factor $\left.-\chi^{(3)} / \alpha\right)$ increased as the Au concentration in $\mathrm{SiO}_{2}$ increased, and reached a maximum value of $1.1 \times 10^{-11}$

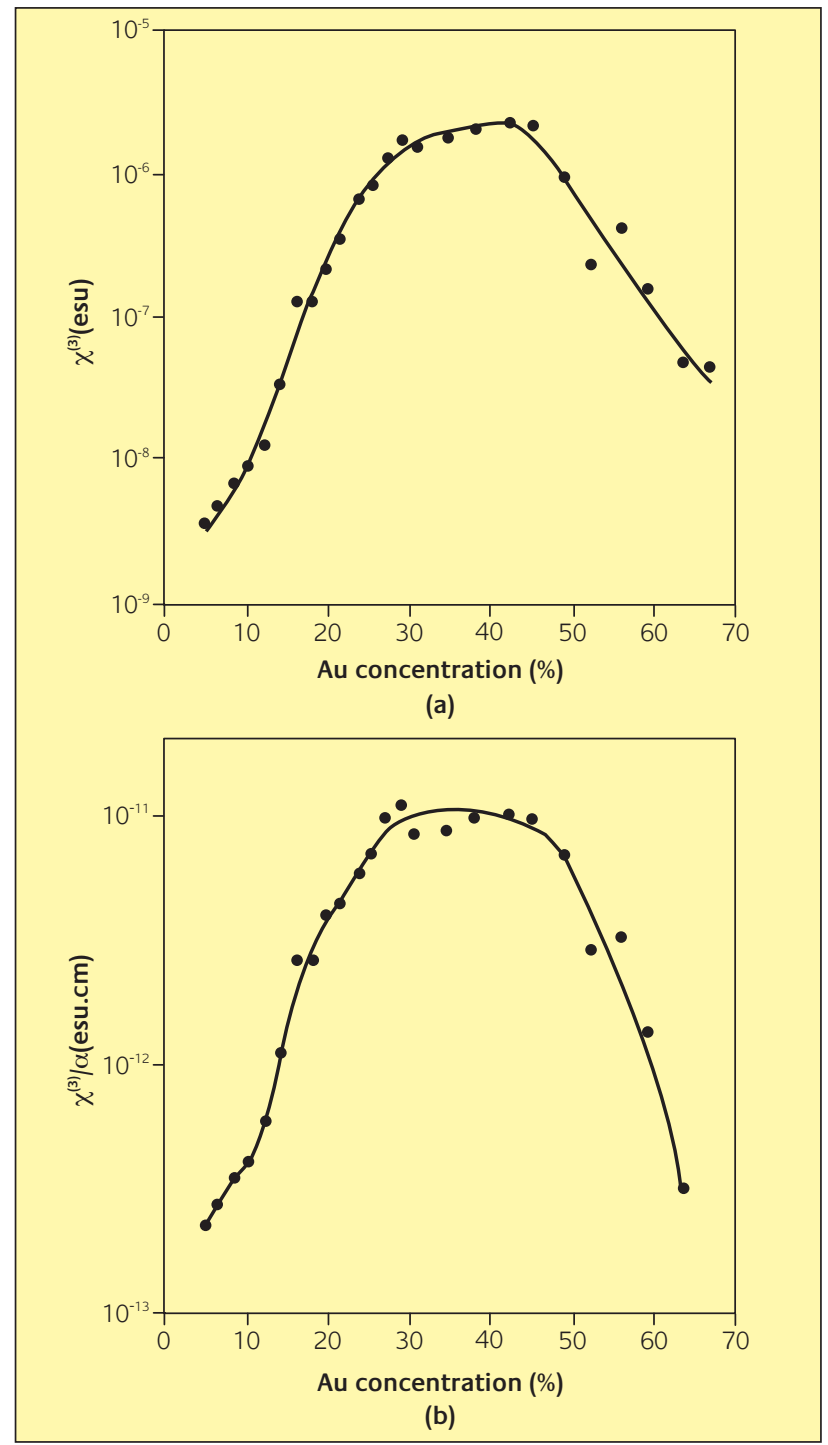

Figure 3

(a) Au-Composition Dependence of $\chi^{(3)}$ and (b) Au-Composition Dependence of $\chi^{(3)} / \alpha$ ( $\alpha$ Absorption Coefficient) in a Au:Sio 2 Composite (48)

(esu.cm) at $\sim 40 \%$ Au, larger than previously reported values (105). They also found that the dependence of the figure of merit $\chi^{(3)} / \alpha$ to the Au concentration also followed a power law, with an exponent of $\sim 2.7$.

Liao et al. (92) reported results for Au: $\mathrm{TiO}_{2}$ composites, shown in Figure 4. They found that at $17 \%$ Au concentration, the wavelength of the SPR was near $665 \mathrm{~nm}$. With increasing Au concentration, the SPR red-shifted, accompanied by a sharpening of the absorption peak. With further Au concentration, the absorption peak started to decrease, and at 60\% Au, the absorption peak disappeared. Liao et al. (92) also measured the $\chi^{(3)}$ and found that at $630 \mathrm{~nm}$, with increasing $\mathrm{Au}$ concentration, $\chi^{(3)}$ increased and reached a maximum of $2.5 \mathrm{x}$ $10^{-7}$ esu at 38\% Au, and then decreased. At $670 \mathrm{~nm}$ (close to the SPR), the same trend was observed, but $\chi^{(3)}$ was larger 


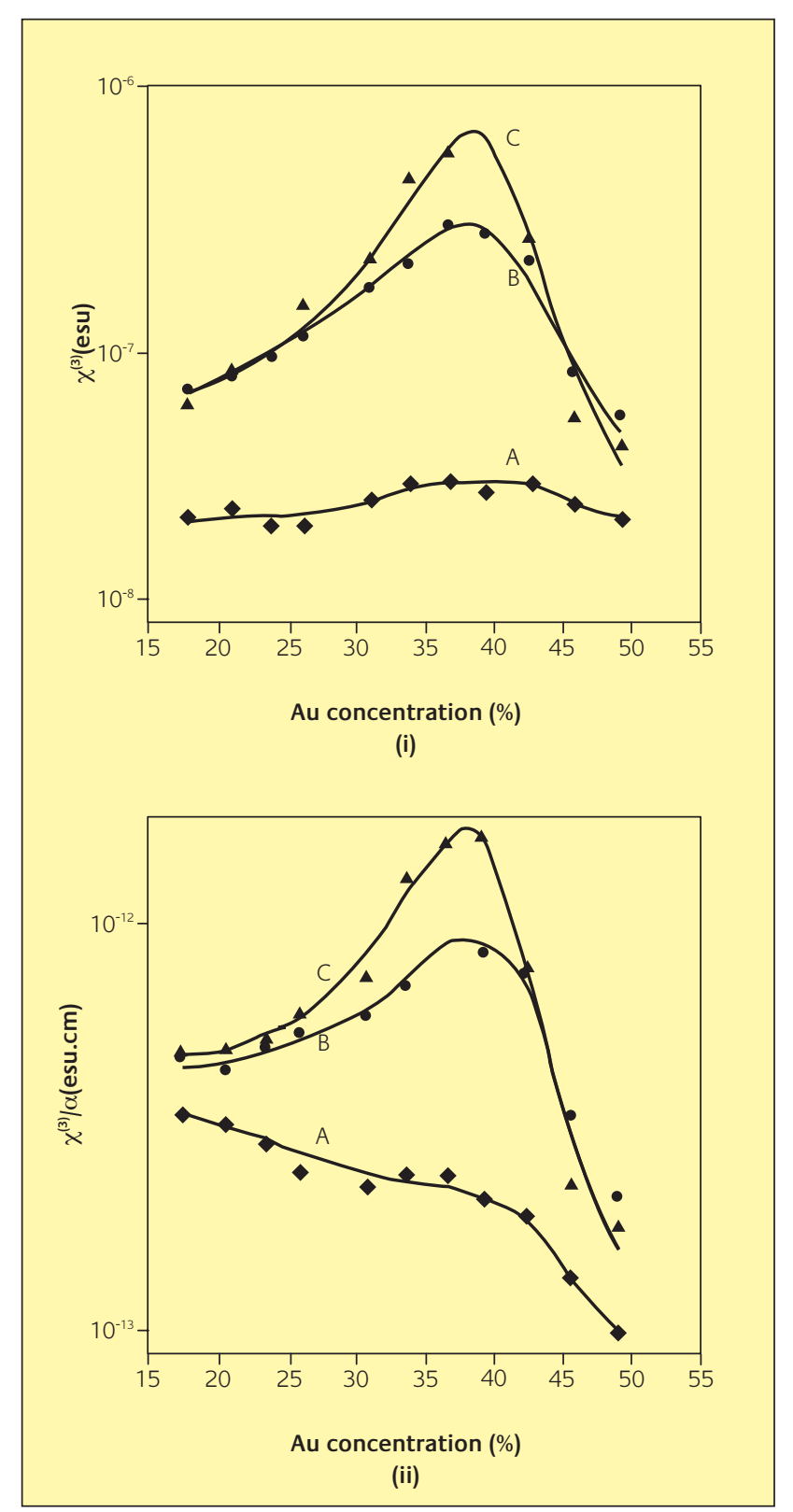

Figure 4

(i) Au-Composition Dependence of $\chi^{(3)}$ and (ii) Au-Composition Dependence of $\chi^{(3)} / \alpha$ ( $\alpha$ Absorption Coefficient) in a Au:Tioz Composite (92) at Wavelengths: (A) $532 \mathrm{Nm}$, (B) $630 \mathrm{Nm}$ and (C) $670 \mathrm{Nm}$

between $26 \% \mathrm{Au}$ and $44 \% \mathrm{Au}$. The maximum $\chi^{(3)}$ was $6 \times 10^{-7}$ esu at $38 \%$ Au. They also found the figure of merit (close to the SPR - $670 \mathrm{~nm}$ ) increased with Au concentration, reached a maximum of $2 \times 10^{-12}$ esu.cm at $38 \%$ Au, then decreased with a further increase in concentration.

Third-order non-linear susceptibility $\left(\chi^{(3)}\right)$ values of $\sim 10^{-8}$ esu have been found for $\mathrm{Au}$ in $\mathrm{Al}_{2} \mathrm{O}_{3}$, for low $\mathrm{Au}$ concentrations $(123,124)$. Liao et al. (125) reported the wavelength of SPR of $\mathrm{Au}$ in $\mathrm{Al}_{2} \mathrm{O}_{3}$ at $550 \mathrm{~nm}$ for $\mathrm{Au}$ concentration of $17 \%$ Au (Figure 5). As the Au concentration increased, the resonance peak shifted to $565 \mathrm{~nm}$ at 40\% Au,

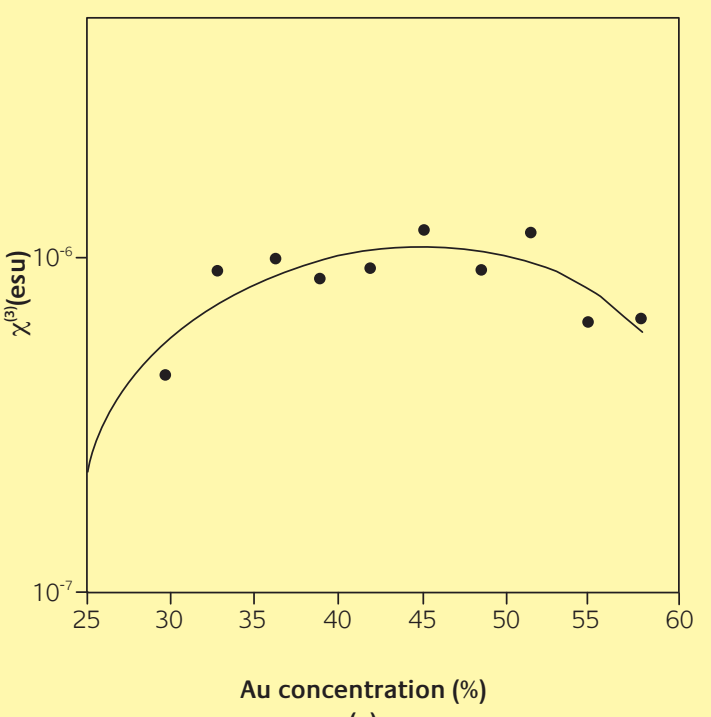

(a)

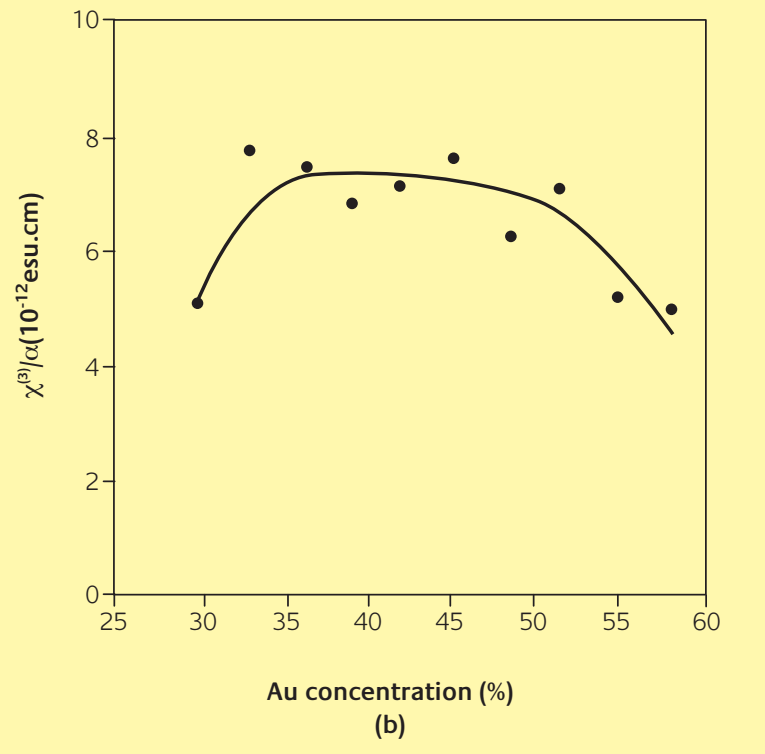

\section{Figure 5}

(a) Au-Composition Dependence of $\chi^{(3)}$ and (b) Au-Composition Dependence of $\chi^{(3)} / \alpha$ ( $\alpha$ Absorption Coefficient) in a Au: $\mathrm{Al}_{2} \mathrm{O}_{3}$ Composite (125)

$575 \mathrm{~nm}$ at 36\% Au and $585 \mathrm{~nm}$ at 42\% Au. Beyond 50\% Au concentration, the peak absorption decreased. In comparison with $\mathrm{Au}: \mathrm{SiO}_{2}$ (48), the SPR in the $\mathrm{Au}: \mathrm{Al}_{2} \mathrm{O}_{3}$ are shifted to longer wavelengths because of the larger dielectric constant of $\mathrm{Al}_{2} \mathrm{O}_{3}$. With an increase in Au concentration, $\chi^{(3)}$ increased and reached a maximum value at $1.2 \times 10^{-6}$ esu at $45 \% \mathrm{Au}$, and then decreased in value (125). Theoretical calculations (126) deviated significantly from the trend of change of $\chi^{(3)}$, although it gave the correct order of magnitude. Liao et al. (125) suggested the enhancement of $\chi^{(3)}$ near the percolation threshold may not be due to the SPR 
of $\mathrm{Au}$, but more likely from the strong interaction between the $\mathrm{Au}$ particles. They also suggested that the matrix contribution $\left(\mathrm{Al}_{2} \mathrm{O}_{3}\right.$ or $\left.\mathrm{SiO}_{2}\right)$ to $\chi^{(3)}$ was negligible in the composite, as it was seven orders of magnitude smaller than that of gold. Liao et al. (125) found that the figure of merit for the $\mathrm{Au}: \mathrm{Al}_{2} \mathrm{O}_{3}$ films increased with Au concentration and

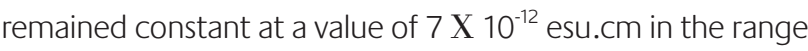
35-50\% Au.

\section{Directions for further study}

A logical question would be how to increase the non-linear properties further. Magruder et al. (127) doped $\mathrm{Ag}$ and $\mathrm{Cu}$ together into glass, and found that the Ag enhanced the response of the Cu near resonance. This would suggest that incorporating another element may increase the non-linear properties further, and give more control of the properties.

Prével et al. (128) have embedded gold, silver and bimetallic silver-gold clusters in a porous alumina matrix, with particle sizes 2-6.7 nm. They suggested the two metals alloyed in the matrix. The two metals were deposited in the ratio 50\% Ag and 50\% Au. The optical absorption band was almost halfway between that of the Au and the Ag. It must be noted that no other ratios were considered, so no conclusion could be drawn about the relationship between the absorption and composition ratio. With decreasing particle size, the Au absorption peak blue-shifts, as well as the Ag:Au absorption peak. They observed that the observed blue-shift trend in the case of the Ag:Au was intermediate between the size evolution obtained in pure $\mathrm{Ag}$ or $\mathrm{Au}$ nanoparticles. TDLDA could theoretically describe the experimental results very well. The SPR position varies strongly as a function of the composition of Ag-Au alloy nanoparticles $(129,130)$. The position varies linearly with gold composition, blue-shifting with decreasing Au mole fraction. This makes the system easily tunable. However, the optical properties should not be viewed as a linear combination of those of pure $\mathrm{Ag}$ and $\mathrm{Au}$, as seen by the inability of the theory to predict the experimental results.

$\mathrm{AuCu}$ and $\mathrm{Au}_{4} \mathrm{Cu}$ nanoparticles were produced in silica thin films using a sol-gel method (131). Absorption peaks were found at $555 \mathrm{~nm}$ for AuCu and at $562 \mathrm{~nm}$ for $\mathrm{Au}_{4} \mathrm{Cu}$, and these absorption peaks are attributed the intermetallic phases.

Henglein and Giersig (132) reported a study of $\mathrm{Au} / \mathrm{Hg}$ nanoparticles in aqueous solution. The optical spectra obtained was not a superpositioning of the individual constituents. This suggested the deposition of $\mathrm{Hg}$ on the gold particles. With increasing $\mathrm{Hg}$ deposition, the plasmon peak blue-shifted and became weaker, and a second broad absorption band builds up in the $300-400 \mathrm{~nm}$ range, without shifting with increasing $\mathrm{Hg}$ content.
Sequential ion implantation has been used to form multicomponent nanometer dimension metal particles in glasses $(133,134)$, which alters the electronic structure of the colloids by changing the composition of the metal particles. This results in changes in the optical properties (both linear and non-linear) that are not possible with single element colloids $(135,136)$.

Zuhr et al. (137) used sequential ion implantation to create intermetallic nanoclusters of $\mathrm{Cd} / \mathrm{Ag}$ and Sb/Ag in silica. Changes in both the linear and non-linear optical properties of the composites could be attained that were not possible with single element colloids alone. The surface plasmon resonance showed significant changes in the wavelength and the magnitude.

From the discussion, it is noted that when incorporating two nanoparticle sized elements in a matrix, either intermetallic nanoparticles form (with their own optical properties) or the one species ends up coating the other (or some other interaction where no intermetallics form). With the above in mind, an interesting investigation would be to embed two elements (which do not form any intermetallic compounds) together in $\mathrm{SiO}_{2}$. The result would be a matrix with two discrete nanoparticle elements. Each element would affect the other species (the effective properties of the composite would change), giving rise to further control of the optical properties. It has been observed that $\mathrm{Ag}$ and Cu particles prepared by the sol-gel process exist as independent particles without forming alloys (138). A logical question that could be asked is: is there a gold analogy, and how would the two nanoparticle species affect each other? Considering the relative simplicity of the sol-gel process, the challenge would be to find a sol-gel process (for producing nanoarticles of Ag, Pt or another element) that is compatible with the sol-gel processes used to produce Au nanoparticles in a glass.

\section{Conclusions}

In this brief review of the non-linear optical properties of $\mathrm{Au}$ nanoparticles, the theory and experimental data of $\mathrm{Au}$ nanoparticles in various substrates have been presented. In the theory section, the basic theories used to model the nanocomposites have been introduced together and the various geometries and the related theory. The methods used to fabricate nanoparticles were discussed in light of mechanical methods (ion-implantation) and chemical methods (sol-gel). The techniques that are used to characterise the nanocomposites were briefly discussed.

The results that have thus far been obtained for $\mathrm{Au}$ in various matrices were presented. The effects of response time, particle size and shape, and concentration were discussed. The effects of adding another element to the nanocomposites were investigated, and it appears that further enhancements in the non-linear properties may occur with multicomponent nanocomposites. 


\section{About the Authors}

Dr. Daven Compton is an engineer in the Physical Metallurgy Division, Mintek, and is interested in the properties of the precious metals and their alloys.

Dr. Lesley Cornish is the head of the advanced materials group, which has interests mainly in the metallurgy of precious metals and their alloys.

Dr. Elma van der Lingen is head of the precious metals group and is involved in the chemistry, physics, metallurgical and catalytic properties of gold.

\section{References}

1 Y.R. Shen, The Principles of Nonlinear Optics, Wiley, New York (1984)

2 J.I. Sakai, Phase Conjugate Optics, McGraw-Hill, Singapore (1992)

3 J. Zyss, Molecular Nonlinear Optics, Academic, New York (1994)

4 R.J. Gehr and R.W. Boyd, Chem. Mater. 8 (1996) 1807

5 R.W. Boyd, R.J. Gehr, G.L. Fischer and J.E. Sipe, Pure Appl. Opt., 5 (1996) 505

6 D.L. Feldheim and C.A. Foss, Metal Nanoparticles: Synthesis, Characterization and Applications, Marcel Dekker, New York (2001)

7 G.W. Arnold and J.A. Borders, J. Appl. Phys. 489 (1977) 1488

8 D.E. Aspnes, Thin Solid Films, 89 (1982) 249

9 D.E. Aspnes, A. Heller and J.D. Porter, J. Appl. Phys. 60 (1986) 3028

10 W.F. Brown, J. Chem. Phys., 23 (1955) 1514

11 C.J.F. Böttcher, Theory of Electric Polarization, Elsevier, New York (1952)

12 Z. Hashin and S.J. Shtrikman, J. Appl. Phys., 33 (1962) 3125

13 D.J. Bergman, J. Phys. Rev. B, 14 (1976) 1531

14 J.C. Maxwell Garnett, Philos. Trans. R. Soc. London, 203 (1904) 385

15 J.C. Maxwell Garnett, Philos. Trans. R. Soc. London, 205 (1906) 237

16 R.W. Cohen, G.D. Cody, D. Coutts and B. Abeles, Phys. Rev. B, 8 (1973) 3689

17 G. Mie, Ann. Phys. 25 (1908) 377

18 H.C. van de Hulst, Light Scattering by Small Particles, Dover, New York (1981)

19 D. Ricard, P. Roussignol and C. Flytzanis, Opt. Lett. 10 (1985) 511

20 G.S. Agarwal and S. Dutta Gupta, Phys. Rev. A, 38 (1988) 5678

21 J.E. Sipe and R.W. Boyd, Phys. Rev. A, 46 (1992) 1614

22 D. Stroud and P.M. Hui, Phys. Rev. B, 37 (1988) 8719

23 X.C. Zeng, D.J. Bergman, P.M. Hui and D. Stroud, Phys. Rev. B, 38 (1988) 10970

24 J.W. Haus, R. Inguva and C.M. Bowden, Phys. Rev. A, 40 (1989) 5729

25 J.W. Haus, N. Kalyaniwalla, R. Inguva, M. Bloemer and C.M. Bowden, J. Opt. Soc. Am. B, 6 (1989) 797

26 A.E. Neeves and M.H. Birnboim, Opt. Lett., 13 (1988) 1087

27 A.E. Neeves and M.H. Birnboim, J. Opt. Soc. Am. B, 6 (1989) 787

28 X. Zhang and D. Stroud, Phys. Rev. B, 49 (1994) 944

29 H.S. Zhou, I. Honma, H. Komiyama and J.W. Haus, Phys. Rev. B, 50 (1994) 12052
30 N. Kalyaniwalla, J.W. Haus, R. Inguva and M.H. Biirnboim, Phys. Rev. A, 42 (1990) 5613

31 M.A. García, J. Llopis and S.E. Paje, Chem. Phys. Lett., 315 (1999) 313

32 F. Hache, D. Ricard, C. Flytzanis and U. Kreibig, Appl. Phys. A. 47 (1988) 347

33 D.A.G. Bruggeman, Ann. Phys. (Leipzig), 24 (1935) 636

34 R. Landauer, J. Appl. Phys., 23 (1952) 779

35 D. Stroud, Phys. Rev. B, 12 (1975) 3368

36 D.E. Aspnes, Am. J. Phys., 50 (1982) 704

37 R.W. Boyd, R.J. Gehr, G.L. Fischer and J.E. Sipe, Pure Appl. Opt., 5 (1996) 505

38 P. Sheng, Phys. Rev. Lett., 45 (1980) 60

39 L. Genzel, T.P. Martin and U. Kreibig, Z. Physik B, 21 (1975) 339

40 L. Gao and Z. Li, Phys. Stat. Sol. (b), 218 (2000) 571

41 F. Hache, D. Ricard and C. Girard, Phys. Rev. B, 38 (1988) 7990

42 F.E. Wagner, S. Haslbeck, L. Stievano, S. Calogero, Q.A. Pankhurst and K.P Martinek, Nature, 407 (2000) 691

43 F. Hache, D. Ricard and C. Flytzanis, J. Opt. Soc. Am. B: Opt. Phys. 3 (1986) 790

44 J. Sasai and K. Hirao, J. Non-Crystalline Solids, 290 (2001) 49

45 H. Wakayabashi, H. Yamanaka, K. Kadono, M. Yamashita, Y. Sakaguchi, T. Akai and M. Miya, Proceedings of 16th International Congress on Glass, Vol. 3. International Committee on Glass, Madrid, Spain (1992) 85

46 O. Maruyama, Y. Senda and S. Omi, J. Non-Crystalline Solids, 259 (1999) 100

47 S. Liberman, X. Quélin, J. Sztern, Y. Dumont, A. Ercheberry, A. Bourbon and P. Gadenne, Eur. Phys. J. AP, 11 (2000) 91

48 H.B. Liao, R.F. Xiao, J.S. Fu, P. Yu, G.K.L. Wong and P. Sheng, Appl. Phys. Lett., 70 (1997) 1

49 B. Palpant, B. Prével, J. Lermé, E. Cottancin, M. Pellarin, M. Treilleux, A. Perez, J.L. Vialle and M. Broyer, Phys. Rev. B, 57 (1998) 1963

50 H. Hövel, S. Fritz, A. Hilger, U. Kreibig and M. Vollmer, Phys. Rev. B, 48 (1993) 18178

51 P. Mélinon, V. Paillard, V. Dupuis, A. Perez, P. Jensen, A. Hoareau, J.P. Perez, J. Tuaillon, M. Broyer, J.L. Vialle, M. Pellarin, B. Baguenard and J. Lermé, Int. J. Mod. Phys. B, 9 (1995) 339

52 A. Perez, P. Mélinon, V. Dupuis, P. Jensen, B. Prevél, J. Tuaillon, L. Bardotti, C. Martet, M. Treilleux, M. Broyer, M. Pellarin, J.L. Vialle, B. Palpant and J. Lermé, J. Phys. D, 30 (1997) 709

53 C.M. Cotell, C.A. Carosella, S.R. Flom, S. Schiestel, N. Haralampus, T.W. Barnett and F.J. Bartoli, Mat. Res. Soc. Symp. Proc. Vol. 396 (1996) 435

54 P. Mazzoldi, G.W. Arnold, G. Bertoncello and F. Gonella, Nucl. Instrum. Meth. B 91 (1994) 478

55 C.W. White, D.S. Zhou, J.D. Budai, R.A. Zuhr, R.H. Magruder III and D.H. Osborne, Mater. Res. Soc. Proc. 316 (1994) 499

56 R.H. Magruder III, R.F. Haglund, L. Yang, J.E. Wittig and R.A. Zuhr, J. Appl. Phys. 76 (1994) 708

57 K. Fukumi, A. Chayahara, M. Adachi, K. Kadono, T. Sakaguchi, Y. Horino, N. Kitamura, J. Hayakawa, H. Yamashita, H. Fujii and M. Satou, Mater. Res. Soc. Symp. Proc. 235 (1992) 389 
58 R.A. Wood, P.D. Townsend, N.D. Skelland, D.E. Hole, J. Barton and C.N. Afonso, J. Appl. Phys. 74 (1993) 5754

59 G.W. Arnold, J. Appl. Phys. 46 (1975) 4466

60 K. Fukumi, A. Chayahara, K. Kadono, T. Sakaguchi, Y. Horino, M. Miya, K. Fujii, J. Hayakawa and M. Satou, J. Appl. Phys. 75(6) (1994) 3075

61 R.H. Magruder III, L. Yang, R.F. Haglund Jr., C.W. White, L. Yang, R. Dorsinville and R. Ralfano, Appl. Phys. Lett. 62 (1993) 1730

62 W.D. Kingery, H.K. Bowen and D.R. Uhlmann, Introduction to Ceramics, 2nd ed. Wiley, New York (1976)

63 C. Wagner, Z. Elektrochem. 65 (1961) 581

64 G.W. Arnold and P. Mazzoldi, pp. 195-222 in: P.Mazzoldi and G.W. Arnold (Eds.), Ion Beam Modification of Classes, Elsevier, Amsterdam (1987)

65 R.A. Weeks, pp. 331-373 in: J. Zarzycki (Ed.), Materials Science and Technology, Vol. 9, VCH, Weinheim (1991)

66 A. Despic and V. Parhutik in: J. O’M. Bockris, R.E. White and B.E. Conway (Eds.), Modern Aspects of Electrochemistry, Plenum Press, New York (1989)

67 M.J. Tierney and C.R. Martin, J. Phys. Chem. 93 (1989) 2878

68 C.A. Foss, Jr., G.L. Hornyak, J.A. Stockert and C.R. Martin, J. Phys. Chem. 98 (1994) 2963

69 G.L. Hornyak, C.J. Patrissi and C.R. Martin, J. Phys. Chem. B, 101 (1997) 1548

70 J. Matsuoka, R. Mizutani, S. Kaneko, H. Nasu, K. Komiya, K. Kadono, T. Sakaguchi and M. Miya, J. Ceram. Soc. Jpn. 101 (1993) 53

71 A. Martino, S.A. Yamanaka, J.S. Kawola, S.K. Showalter and D.A. Loy, US Patent 5,814,370 (1998)

72 S. Otsuki, K. Nishio, T. Kineri, Y. Watanabe and T. Tsuchiya, J. Am. Ceram. Soc. 82 (1999) 1676

73 Y. Hosoya, S. Ohsugi, S. Muto and Y. Kurokawa, Thin Solid Films, 883 (1996) 221

74 Y. Kurokawa, Y. Kobayashi and S. Nakata, Heterogenous Chem. Rev., 1 (1994) 309

75 Y. Hosoya, T. Suga, T. Yanagawa and Y. Kurokawa, J. Appl. Phys., 81 (1997) 1475

76 S.T. Selvan, M. Nogami, A. Nakamura and Y. Hamanaka, J. NonCrystalline Solids, 255 (1999) 254

77 M. Epifani, C. Giannini, L. Tapfer and L. Vasanelli, J. Am. Ceram. Soc., $83(2000) 2385$

78 T.J. Norman Jr., C.D. Grant, D. Magana, J.Z. Zhang, J. Liu, D. Cao, F. Bridges and A. Van Buuren, J. Phys. Chem. B, 106 (2002) 7005

79 H. Mori and H. Yasuda, Mat. Sci. Eng. A, 312 (2001) 99

80 B.D. Cullity, Elements of X-ray Diffraction, 2nd ed. Addison-Wesley (1978)

81 A.L. Smirl, T.F. Bogess and F.A. Hopf, Opt. Commun. 34 (1980) 463

82 Y.M. Cheung, S.K. Gayen, J. Opt. Soc. Am. B, 11 (1994) 636

83 D.D. Smith, Y. Yoon, R.W. Boyd, J.K. Campbell, L.A. Baker, R.M. Crooks and M. George, J. App. Phys., 86 (1999) 6200

84 M. Quinten, Z. Phys. B, 101 (1996) 211

85 M.L. Thèye, Phys. Rev B. 2 (1970) 3060

86 P.B. Johnson and R.W. Christy, Phys Rev. B. 6 (1972) 4370

87 A.S. Barker, Phys. Rev. B. 8 (1973) 5418
88 W.H. Weber and S.L. McCarthy, Phys. Rev. B. 12 (1975) 5643

89 S. Berthier and J. Peiro, J. Phys.: Condens. Matter, 10 (1998) 3679

90 R.A. Innes and J.R. Sambles, J. Phys. F: Met. Phys. 17 (1987) 277

91 N.A. Papadogiannis, P.A. Loukakos and S.D. Moustaizis, Optics Communications, 166 (1999) 133

92 H.B. Liao, R.F. Xiao, H. Wang, K.S. Wong and G.K.L. Wong, Appl. Phys. Lett., 72 (1998) 1817.

93 H.B. Liao, R.F. Xiao, J.S. Fu, H. Wang, K.S. Wong and G.K.L. Wong, Opt. Lett., 23 (1998) 388

94 K. Puech, F.Z. Henari, W.J. Blau, D. Duff and G. Schmid, Chem. Phys. Lett., 247 (1995) 13

95 T.S. Ahmadi, S.L. logunov and M.A. El-Sayed, J. Phys. Chem., 100 (1996) 8053

96 R.H. Doremus, J. Chem. Phys., 40 (1964) 2389

97 R.H.M. Groeneveld, R. Sprik and A. Lagedijk, Phys. Rev. B, 51 (1995) 11433

98 M. Perner, P. Bost, U. Lemmer, G. von Plessen, J. Feldmann, U. Becker, M. Mennig, M. Schmitt and H. Schmidt, Phys. Rev. Lett., 78 (1997) 2192

99 J.H. Hodak, A. Henglein and G.V. Hartland, J. Chem. Phys., 112 (2000) 5942

100 H. Inouye, K. Tanaka, I. Tanahashi and K. Hirao, Phys. Rev. B, 57 (1998) 11334

101 S. Link and M.A. El-Sayed, J. Phys. Chem. B, 103 (1999) 8410

102 S. Muto, T. Kubo, Y. Kurokawa and K. Suzuki, Thin Solid Films, 322 (1998) 233

103 K. Fukumi, A. Chayahara, K. Kadono, T. Sakaguchi, Y. Horino, M. Miya, J. Hayakawa and M. Sato, Jpn. J. Appl. Phys. 30 (1991) L742

104 M. Mennig, M. Schmitt, T. Burkhart, U. Becker and H. Schmidt, Proc. SPIE, 2288 (1994) 130

105 I. Tanahashi, Y. Manabe, T. Tohda, S. Sasaki and A. Nakamura, J. Appl. Phys. 79 (1996) 1244

106 T. Yazawa, K. Kadono, H. Tanaka, T. Sakuguchi, S. Tubota, K. Kuraoka, M. Miya and W. De-Xion, J. Non-Cryst. Solids, 170 (1994) 105

107 M. Lee, T.S. Kim and Y.S. Choi, J. Non-Cryst. Solids, 211 (1997) 143

108 J. Matsuoka, R. Mizutani, S. Kaneko, H. Nasu, K. Komiya, K. Kadono, T. Sakaguchi and M. Miya, J. Ceram. Soc. Jpn. 101 (1993) 53

109 T. Kineri, Ph.D. Thesis, Science University of Tokyo, Nodashi, Japan (1994)

110 M.W. Jung, J.E. Kim and K.C. Lee, J. of the Korean Chem. Soc. 44(1) (2000) 60

111 R.H. Doremus, J. Chem. Phys. 40 (1964) 2389

112 U. Kreibig, J. Phys. (Paris), C2 (1977) 97

113 C.V. Fragstein and H. Römer, Z. Phys. 151 (1958) 54

114 M.J. Bloemer, J.W. Haus and P.R. Ashley, J. Opt. Soc. Am. B. 7 (1990) 790

115 M.M. Alvarez, J.T. Khoury, T.G. Schaaff, M.N. Shafigullin, I. Vezmar and R.L. Whetten, J. Phys. Chem. B, 101 (1997) 3706

116 M.B. Mohamed, S. Link and M.A. El-Sayed, J. Phys. Chem. B, 102 (1998) 9370

117 S. Link, M.B. Mohamed and M.A. El-Sayed, J. Phys. Chem. B, 103 (1999) 3073

118 C.A. Foss Jr., M.J. Tierney and C.R. Martin, J. Phys. Chem. 96 (1992) 9001

119 C.G. Granqvist and O. Hunderi, Phys. Rev B. 16 (1977) 1353 
120 E.J. Zeman and G.C. Schatz, J. Phys. Chem. 91 (1987) 634

121 P. Sheng, Phys. Rev. Lett., 45 (1980) 60

122 M. Ando, K. Kadono, M. Haruta, T. Sakaguchi and M. Mlya, Nature (London), 374 (1995) 625

123 C.W. White, D.K. Thomas, D.K. Hensley, R.A. Zuhr, J.C. McCallum, A. Pogany, R.F. Haglund, R.H. Magruder and L. Yang, Nanostructured Materials, 3 (1993) 447

124 Y. Hosoya, T. Yanagawa and Y. Kurokawa, J. Appl. Phys., 81 (1997) 1475.

125 H.B. Liao, R.F. Xiao, J.S. Fu and G.K.L. Wong, Appl. Phys. B, 65 (1997) 673

126 G.S. Agarwal, S.D. Gupta, Phys. Rev. A, 38 (1988) 5678

127 R.H. Magruder III, D.H. Osborne, Jr. and R.A. Zuhr, J. Non-Crys. Solids, 176 (1994) 299

128 B. Prével, J. Lermé, M. Gaudry, E. Cottancin, M. Pellarin, M. Treilleux, P. Mélinon, A. Perez, J.L. Vialle and M. Broyer, Scripta mater., 44 (2001) 1235

129 M. Treguer, C. de Cointet, H. Remita, J. Khatouri, M. Mostafavi, J. Amblard, J. Belloni and R. de Keyzer, J. Phys. Chem B, 102 (1998) 4310
130 S. Link, Z.L. Wang and M.A. El-Sayed, J. Phys. Chem B, 103 (1999) 3529.

131 J. Gwak, S. Kim and M. Lee, J. Phys. Chem B 102 (1998) 7699

132 A. Henglein and M. Giersig, J. Phys. Chem. B, 104 (2000) 5056

133 R.H. Magruder III, J.E. Wittig and R.A. Zuhr, J. Non-Cryst. Solids 163 (1993) 162

134 R.A. Zuhr, R.H. Magruder III and J.E. Wittig, Mater. Res. Soc. Sym. Proc. 316 (1994) 457

135 R.H. Magruder III, T.S. Anderson, R.A. Zuhr and D. Thomas, Nucl. Instrum. Meth B 108 (1996) 305

136 T.S. Anderson, R.H. Magruder III, D.L. Kinser, R.A. Zuhr and D. Thomas, Nud. Instrum. Meth. B. 124 (1997) 40

137 R.A. Zuhr, R.H. Magruder III and T.S. Anderson, Surface and Coatings Technology 103-104 (1998) 401

138 G. De, L. Tapfer, M. Catalano, G. Battaglin, F. Caccavale, P. Mazzoldi and R.F. Haglund, Appl. Phys. Lett. 68 (1996) 3820

\section{NEW:}

\section{Handbook on Investment Casting}

The latest technical handbook on gold jewellery manufacture has just been published and launched at the Santa Fe Symposium in May. Seventh in the series of technical manuals and handbooks from World Gold Council, the new Handbook on Investment Casting, written by Dr V.Faccenda, with a chapter on casting alloys by

Dieter Ott (formerly of FEM, Germany), is a comprehensive book on the latest technology developments and manufacturing best practice on the most widely used process in jewellery manufacture (also known as the lost wax casting process). Lavishly illustrated in colour, the Handbook comprises about 100 pages in 6 chapters, describing the various steps in the investment casting process (with guidelines and pitfalls), alloys for investment casting, equipment, list of manufacturers and suppliers and a comprehensive list of further reading. For those involved in investment casting of jewellery, this book is an essential tool.

The Handbook costs $£ 16 / \$ 26 / € 26$ and the English edition is available now (the Italian edition will be available later this summer) from:

World Gold Council

International Technology (Publications)

45 Pall Mall

London SW1Y 5JG

U.K.

Tel: +442079305171

Fax: +44 2078396561

E-mail: industry@gold.org

Payment by cheque or money order or direct into the WGC bank account (details on request). 